MARIANA SVERLIJ

UNIVERSIDAD DE BUENOS AIRES

\title{
La ruina, el diseño y los materiales en De re æedificatoria de Leon Battista Alberti
}

\author{
La arquitectura y la ruina
}

$\mathrm{E}$ n su análisis de la obra de Aristóteles, Jean Brun subraya el nexo que se establece entre la física y la cosmología aristotélica, aduciendo que el finalismo de la primera no representa un determinismo perfecto: "la materia opone a la forma una resistencia que la actualiza e introduce cierto elemento de indeterminación que no se encuentra sino en el mundo sublunar” , ' caracterizado éste por la presencia del cambio y de lo indeterminado. En una remisión a la cosmología aristotélica, Alberto Cassani llama, en este sentido, "sublunar" al mundo humano descrito por Alberti, un mundo sujeto a la voracidad del cambio, expresado en los ciclos adversos de la fortuna y la decadencia fatal de los hombres y de las cosas. ${ }^{2}$ Esta exposición del "mundo sublunar" encuentra, desde mi perspectiva, una expresión acabada en la idea de ruina. Es la ruina, que Alberti y sus contemporáneos encuentran diariamente en el marco de sus paseos por Roma y de sus "excavaciones" arqueológicas y filológicas, la que manifiesta el seguro destino de todas las cosas. Pero Alberti reconoce en las ruinas no sólo el motivo de su melancolía, sino también el verdadero motor que lo impulsa a la

I. Jean Brun, Aristóteles y el Liceo (Buenos Aires: EudeBA, 1985), 76.

2. Alberto Cassani, La fatica del costruire. Tempo e materia nel pensiero di Leon Battista Alberti (Milán: Unicopli, 2004). 
reflexión y a la escritura. De este modo se expresa en el inicio del libro VI de su tratado de arquitectura, De re adificatoria:

Sobrevivían aún ejemplos de antiguas obras, como teatros y templos, de los que, como de insignes profesores, sería posible aprender mucho: veía, no sin lágrimas en los ojos, cómo iban siendo destruidos día a día; y que quienes, acaso, llevaban a cabo una construcción contemporáneamente, se inspiraban más en tonterías y extravagancias de moda, que en seguir los criterios ya ampliamente probados en las obras más elogiadas; por todo lo cual, nadie negaba que, en breve tiempo, esta, por así decir, parte de la vida y del conocimiento, habría, seguramente, desaparecido del todo. Siendo ésta la situación, no podía sino ponerme a meditar con gran frecuencia y durante largo tiempo, sobre la posibilidad de comentar estos temas. ${ }^{3}$

La ruina emerge como el fundamento primero de la teoría arquitectónica albertiana. Alberti recuerda con orgullo, a lo largo de su tratado, todo aquello que aprendió - y se propone transmitir- observando, dibujando, tomando nota de las construcciones antiguas que seguían en pie, así como de sus restos que aún hablaban. En este sentido, la ruina expresa un modelo y una moraleja: es la potencia vuelta acto (tendiente no a la perfección sino al desbaratamiento) y la firme consecuencia de un tiempo que todo lo devora, en sintonía con la violencia de la historia. En el comienzo del último libro de su tratado Alberti reflexiona:

El tiempo todo lo vence; y pérfidas y demasiado vigorosas son las armas de la vejez; ni pueden los cuerpos hacer nada contra las leyes de la naturaleza que los lleva a envejecer [...]. Percibimos cuánto poder tiene el ardor del sol, la gélida sombra, las heladas, los vientos [...]. Ańade a ello los dańos provocados por los hombres. ${ }^{4}$

3. "Restabant vetera rerum exempla templis theatrisque mandata, ex quibus tanquam ex optimis professoribus multa discerentur: eadem non sine lachrymis videbam in dies deleri; et qui forte per haec tempora aedificarent, novis ineptiarum //deliramentis potius quam probatissimis laudatissimorum operum rationibus delectari; quibus ex rebus futurum negabat nemo, quin brevi haec pars, ut ita loquar, vitae et cognitionis penitus esset interitura. Idcirco haec cum ita essent, non poteram non facere, quin de commentandis his rebus et saepe et diu cogitarem”. Leon Battista Alberti, De re adificatoria, ed. Giovanni Orlandi (Milán: Il Polifilo, I966), VI, I, 44I-443. Donde no se aclare algo contrario, las traducciones al castellano son siempre mías. Cotejé las de los pasajes expuestos de De re adificatoria con la versión italiana de G. Orlandi y la castellana con traducción de J. Fresnillo: Leon Battista Alberti, De re adificatoria (Madrid: Akal, I991).

4. "omnia vinci aevo; et insidiosa nimiumque valida esse tormenta vetustatis; nec posse ad- 
Es, en fin, a partir de la ruina — con su condensación del espacio y del tiempocomo Alberti escoge pensar y pensarse, en tanto arquitecto y teórico de las artes, en tanto escritor y matemático.

En el Origen del Trauerspiel alemán, Walter Benjamin sentencia que:

en el semblante de la naturaleza está escrita la palabra "historia" con la escritura cifrada de la transitoriedad: la fisonomía alegórica de la historia natural, que es puesta en escena por el Trauerspiel, está realmente presente como ruina [...]. Así configurada, la historia no se manifiesta como proceso de una vida eterna, sino como transcurso de ineluctable decadencia. ${ }^{5}$

Para los escritores barrocos, de acuerdo con Benjamin:

los elementos que ha legado la antigüedad son [...], pieza por pieza, aquéllos a partir de los cuales se combina la nueva totalidad. Mejor dicho: se construye. Pues la visión perfecta de esta nueva totalidad es la ruina [...]. Aquella técnica, que en el plano del detalle se refería con ostentación a las cosas concretas, a las flores retóricas y a las reglas, estaba orientada a un efusivo dominio de los elementos antiguos en una construcción que, sin unirlos en un todo, seguirá siendo superior, en la destrucción, a las antiguas armonías. ${ }^{6}$

Alberti coloca, al lado del rostro de la destrucción, el de la armonía, en una balanza depositada en las manos del hombre. Si a lo largo de su tratado de arquitectura discurre sobre el arte de construir esa armonía (el ensamblaje de las partes en un todo armónico), lo hace con la perenne conciencia de la fragilidad de la materia y de la acción devastadora del hombre y de la naturaleza. Dicho en otros términos, el humanista nacido en Génova excluye la presencia de un modelo, ajeno a la inmanencia del mundo terreno. Elige, en su lugar, uno que ofrece la ruina, $y$, a diferencia del tratamiento dado por el barroco en la argumentación benjaminiana, desde los ciclos de generación y corrupción del mundo, busca instalar ciertos principios de estabilidad. En la búsqueda de estos principios, la

versus foedera naturae nisi corpora, quin senectutem subeant [...]. Sentimus, quid ardor solis, quid umbrae gelatio, quid pruniae, quid venti valeant. [...]. Adde his hominum iniurias". Alberti, De re edificatoria, X, I, 869.

5. Walter Benjamin, Origen del Trauerspiel alemán, trad. Carola Pivetta (Buenos Aires: Gorla, 20I2), 22 I.

6. Benjamin, Origen del Trauerspiel alemán, 222. 
teoría arquitectónica albertiana expresa su objetivo mayor. La ruina, por tanto, no es el final del recorrido, el rostro de la historia que expresa la escena barroca, sino un eterno lugar de comienzo y una conciencia que subyace en la historia construida y vuelta a construir.

\section{El diseño}

Estos principios de estabilidad son concebidos en la mente del arquitecto, quien los vuelca en su obra, destinada a emitir los fundamentos, pero también los límites de la razón humana. Alberti expone estos fundamentos en el prólogo a De re adificatoria, donde comienza por definir al actor y al objeto de la arquitectura: el arquitecto y el edificio. Una vez asentada la preeminencia de la arquitectura sobre las otras artes, Alberti define al arquitecto, al que diferencia del obrero (fabrum):

Yo, por mi parte, determinaré que el arquitecto será aquel que con un método (via) admirable y riguroso sepa proyectar racionalmente y realizar prácticamente cualquier obra que, a partir del desplazamiento de los pesos y la reunión y encadenamiento de los cuerpos, se adapte bellamente (bellisime) a las necesidades (usibus) más propias del hombre. Para hacerlo posible, necesita del conocimiento de las más importantes disciplinas. ${ }^{7}$

El arquitecto, por tanto, además de abocarse a la dimensión práctica de la arquitectura, tiene un doble compromiso intelectual, en tanto mentor de la obra y conocedor de las más importantes disciplinas. Alberti justifica estos atributos que debe tener el arquitecto dando, a continuación, su propia versión, diferente de la de Vitruvio, ${ }^{8}$ de los orígenes de la arquitectura y del papel necesario

7. "Architectum ego hunc fore constituam, qui certa admirabilique ratione et via tum mente animoque deffinire tum et opere absolvere didicerit, quaecunque ex ponderum motu corporumque compactione et coagmentatione dignissimis hominum usibus bellissime commodentur. Quae ut possit, comprehensione et cognitione opus est rerum optimarum et dignissimarum". Alberti, De re adificatoria, pról., 7.

8. Alberti toma distancia de la teoría de Vitruvio, para quien el origen del agrupamiento humano derivó del descubrimiento del fuego. Por el contrario, para Alberti, éste se produce merced a la arquitectura, tal como lo expresa en el prólogo a De re adificatoria: "Hubo quienes decían que el agua o el fuego fueron las causas originarias que permitieron el agrupamiento en 
que desempeńa en el desarrollo y disfrute de la vida individual y social de los hombres, declarando, por ello mismo, haber asumido la tarea de reunir en diez libros los contenidos propios de este arte. ${ }^{9}$ Establecido este carácter necesario de la arquitectura y el valor de la obra que está por emprender, agrega a la definición de arquitecto arriba citada la concerniente al edificio:

En efecto, como hemos advertido, un edificio (aedificium) es, ciertamente, un cuerpo (corpus), que, como los otros cuerpos, consta de diseńo (lineamentis) y materia, de los cuales uno es producido por la inteligencia (ingenio), la otra es fruto de la naturaleza (natura); a éste hemos de proporcionar la mente y la razón (mentem cogitationemque), a esta otra la preparación y la selección. Sin embargo, ni una ni otra acción bastarán por sí solas, si no se añaden las experimentadas manos del artífice, capaces de dar forma a la materia mediante el diseño (lineamentis materiam). ${ }^{\text {Io }}$

comunidades de los seres humanos. Pero nosotros, considerando la utilidad del techado y la pared y su carácter necesario, estamos convencidos de que estos últimos factores, sin duda alguna, tuvieron un mayor peso a la hora de reunir (conciliandos) y mantener juntos (continendos) a los seres humanos". ("Fuere qui dicerent aquam aut ignem //praebuisse principia, quibus effectum sit, ut hominum coetus celebrarentur. Nobis vero tecti parietisque utilitatem atque necessitatem spectantibus ad homines conciliandos atque una continendos maiorem in modum valuisse nimirum persuadebitur”.) Alberti, De re adificatoria, pról., 9. En efecto, para Alberti, no es a partir de las manifestaciones de la naturaleza (representadas, en el caso vitruviano, por el fuego) como el hombre se aglutina en una comunidad, sino a partir del límite que éste impone a la naturaleza, vale decir, de las propias herramientas que diseña para mantenerse a resguardo y a distancia de ella.

9. De re adificatoria, emulando el De architectura libri decem de Vitruvio, se compone de diez libros. El propio Alberti especifica el contenido de cada uno de estos libros: en el primero se dedicará al "diseño" (lineamenta), en el segundo, a los “materiales” (materia), en el tercero, a la "obra" (opus), en el cuarto, a las "obras de uso común" (universorum opus), en el quinto, a las "obras de uso restringido" (singulorum opus), en el sexto, a la "ornamentación” (ornamentum), en el séptimo, a la "ornamentación de los edificios religiosos" (sacrorum ornamentum), en el octavo, a la "ornamentación de los edificios públicos civiles" (publici profani ornamentum), en el noveno, a la "ornamentación de las construcciones privadas" (privatorum ornamentum) y en el décimo, al "mantenimiento de los edificios" (operum instauratio). Alberti menciona también un apéndice que versará sobre "la nave" (navis), "la financiación" (aeraria), "la aritmética y la geometría" (historia numeri et linearum), "sobre lo que pueda serle útil al arquitecto en su trabajo" (quid conferat architecto in negocio), y que no ha quedado registrado.

Io. "Nam aedificium quidem corpus quoddam esse animadvertimus, quod lineamentis veluti alia corpora constaret et materia, quorum alterum istic ab ingenio produceretur, alterum a natura susciperetur: huic mentem cogitationemque, huic alteri parationem selectionemque adhibendam; sed utrorumque per se neutrum satis ad rem valere intelleximus, ni et periti artificis manus, quae lineamentis materiam conformaret, accesserit”. Alberti, De re adificatoria, pról., I5. 
A partir de estas dos definiciones Alberti desarrolla un concepto central para su teoría de la arquitectura, al que llama lineamenta, y del cual se ocupará, específicamente, en el libro primero, sin dejar, sin embargo, de remitir a él a lo largo de todo su tratado. ${ }^{\text {II }}$

Pero ¿cómo traducir y comprender este concepto central de la teoría arquitectónica albertiana? Javier Fresnillo, en su traducción castellana del tratado albertiano, traduce lineamenta como "trazado". Giovanni Orlandi, en su traducción italiana escoge, en cambio, el término "disegno" (en italiano: dibujo). ${ }^{\mathrm{I2}}$ Yo opté por "diseño", que incluye el plano material del dibujo concreto tanto como la impronta de una mente que lo ha elaborado. En todo caso, más allá de la tra-

I I. La centralidad de este concepto se advierte también en Momus, la narración que Alberti compone entre I443 y I450. Allí, el filósofo Gelasto desarrolla una intrincada teoría sobre el origen del mundo humano, a la que el barquero Caronte no encuentra sentido, esgrimiendo en su lugar las observaciones hechas por un pintor, quien, lineamentis contemplandis, había reconocido el origen enmascarado del mundo humano. De acuerdo con la lectura de Caronte, es allí donde residen los fundamentos de la obra (en este caso, el hombre), su verdad engañosamente expresada. Reproducimos aquí las palabras proferidas por Caronte: “Te contaré lo que recuerdo del discurso, no de un filósofo, ya que todas vuestras reflexiones giran en torno a sutilezas y juegos de palabras, sino de un pintor. Después de observar a lo largo de mucho tiempo las formas del cuerpo, él sí que vio por sí solo más que todos ustedes juntos, midiendo e investigando sobre el cielo". ("Referam quae non a philosopho — nam vestra omnis ratio nisi in argutiis et verborum captiunculis versatur - sed a pictore quodam memini audivisse. Is quidem lineamentis contemplandis plus vidit solus quam vos omnes philosophi caelo commensurando et disquirendo"). Leon Battista Alberti, Momus, ed. Virginia Brown y Sarah Knight (Londres: The I Tatti Renaissance Library, 2003), 306-308.

I2. En nota al pie se justifica del siguiente modo la elección del término "disegno": "Con el término lineamenta A. refiere a algo menos amplio y más específico que el italiano 'dibujo'. Sin embargo, al traducir 'proyecto' y 'proyectar', se alteraría en cierto punto el sentido del texto. Se prefirió, por tanto, traducir literalmente porque, pocas páginas después, el lector será conducido, por el propio uso que A. hace del término, a restringir y especificar el significado”. Alberti, De re adificatoria, pról., I8. Por su parte, Betts señala cuáles fueron las sucesivas traducciones del término al italiano y al inglés: "El término es difícil de traducir. [...] Cosimo Bartoli, en I550, tradujo lineamentis como 'disegno', como hace Giovanni Orlandi, en la última traducción, aunque con dudas [...]. En I720, el primer traductor inglés, James Leoni, siguiendo a Bartoli, tradujo lineamentis al inglés como 'design'. [...]. En la más reciente traducción al inglés, Rykwert, Tavernor y Leach transliteraron lineamentis al inglés como 'lineaments'. La transliteración puede ser cuestionable como forma de traducción, pero no aparecen alternativas razonables que sean válidas". Richard Betts, "On Lineamentis: Alberti's Definitions as the Intellectual Structure of De re adificatoria", en Leon Battista Alberti, teorico delle arti e gli impegni civili del "De re adificatoria" (I), eds. Arturo Calzona, Paolo Fiore et al. (Città di Castello: Leo S. Olschki, 2007), 424-425. 
ducción del término, en este caso, siempre incompleta respecto del significado original, la comprensión acabada de este concepto se desprende de las propias palabras albertianas. Alberti, en efecto, según se ha podido observar, da cuenta de dos instancias diferenciadas que involucran todo proceso constructivo, de las que se ocupará por separado en los libros primero y segundo: lineamenta y materia. La segunda, dice, es fruto de la naturaleza, en tanto la primera deriva de la inteligencia. Dicho en otras palabras, la materia (los materiales) existe antes de su "preparación y selección", mientras que el diseńo lleva siempre y desde siempre la impronta del raciocinio del hombre: es en la medida en que éste lo ha elaborado. Es por ello que, si bien la complementación del diseńo y los materiales, por medio de las manos del artífice, es la condición de posibilidad de toda construcción, Alberti puede separarlos en dos momentos distintos: "el arte de la construcción en su conjunto se compone del diseño y de la construcción", I3 pero "se podrán proyectar en mente y espíritu (animo et mente) las formas en su totalidad, prescindiendo completamente de los materiales" ${ }^{14}$ Este "armado mental" de la obra está presente también en el tratado vitruviano. En el capítulo XI del libro VI, dedicado a la firmeza de los edificios, Vitruvio distingue tres valoraciones distintas a las que se puede arribar contemplando el aspecto de un edificio: cuando éste es de aspecto magnífico, dice el arquitecto romano, lleva a apreciar el material del que está compuesto, si lo que se valora, en cambio, es la sutileza del trabajo, la admiración la llevará la destreza del albañil; si, finalmente, lo que se aprecia es la elegancia que procede de la exactitud de las proporciones, el mérito será del arquitecto. En verdad, señala, no sólo los arquitectos, sino todos los hombres pueden reconocer lo que es bueno. La diferencia radica en que esta apreciación general surge de la contemplación de un edificio materializado, en cambio, el arquitecto no parte de la conclusión sino de la concepción: "pero el arquitecto, luego de haberla ideado en su mente, sabe lo que será después de concluida, en gracia, comodidad y decoro". ${ }^{\text {Is }}$ De una forma en cierto modo

I3. "Tota res ædificatoria lineamentis et structura constituta est”. Alberti, De re adificatoria, I, I, I9.

I4. "Et licebit integras formas praescribere animo et mente seclusa omni materia". Alberti, De re edificatoria, I, I, 2 I.

I5. "architectus autem, simul animo constituerit, antequam inceperit, et venustate et usu et decore quale sit futurum, habet definitum". Pollio Vitruvius, De architectura libri decem, ed. F. Krohn (Leipzig: Teubner, I9 I 2), 6.8. Io. http://data.perseus.org/texts/urn:cts:latinLit:phil I056. phioo r.perseus-lat I. Las citas en castellano de este texto corresponden a: Marco Polión Vitruvio, Los diez libros de arquitectura (Madrid: Akal, 2007), VI, XI, I60. La edición de Akal 
similar, Alberti desarrolla su definición de lineamenta, partiendo de la conciencia de representar una fase inicial que contempla el armado final:

En cuanto al diseño toda su fuerza y razón (vis et ratio) consisten en encontrar un modo exacto y satisfactorio de ajustar y unir líneas y ángulos, por medio de los cuales resulte enteramente definido el aspecto del edificio. Es, por tanto, labor y función del diseño asignar a los edificios y a las partes que los componen un lugar conveniente (aptum locum), una proporción determinada (certum numerum), una disposición decorosa (dignumque modum) y una distribución agradable (gratum ordinem), de modo que la forma entera de la construcción repose en el diseńo mismo. ${ }^{16}$

El concepto de lineamenta refiere, por tanto, a la juntura de líneas y ángulos, tanto como a las distintas partes que conforman el edificio, su ubicación, proporcionalidad, funcionalidad y decoro. En el libro noveno, dedicado al ornamento, Alberti retoma y amplía esta definición, incluyéndola como partícipe necesaria de la conformación de las cosas bellas:

Aquello que se aprecia en las cosas más hermosas y adornadas es fruto, o bien de la invención o de las previsiones de la inteligencia, o bien del trabajo del artífice, o bien ha sido infundido a tales cosas directamente por la naturaleza. Propias de la inteligencia serán la elección, la distribución, la disposición, etc., para darle decoro a la obra; propios del obrero serán el acumular, el aplicar, el cortar, el recortar, el revocar, etc., para dotar de gracia a la obra; de la naturaleza se recibirán la pesadez, la ligereza, la densidad, la pureza, la resistencia al paso del tiempo, y otras semejantes, que hacen que la obra resulte admirable. Estas tres funciones deben ser aplicadas en las partes del edificio según el empleo y destino de cada una. ${ }^{17}$

reproduce la traducción de José Ortiz y Sanz de 1787.

I6. "Lineamentorum omnis vis et ratio consumitur, ut recta absolutaque habeatur via coaptandi iungendique lineas et //angulos, quibus aedificii facies comprehendantur atque concludatur. Atqui est quidem lineamenti munus et officium praescribere aedificiis et partibus aedificiorum aptum locum et certum numerum dignumque modum et gratum ordinem, ut iam tota aedificii forma et figura ipsis in lineamentis conquiescat”. Alberti, De re adificatoria, I, I, I9.

I7. "Quae in rebus pulcherrimis et ornatissimis placeant, ea quidem aut ex ingenii commento et rationibus aut ex artificis manu deveniunt, aut a natura rebus ipsis immissa sunt. Ingenii erit electio distributio collocatio et eiusmodi, quae operi afferant dignitatem; manus erit acervatio affictio amputatio circumcisio expolitio et generis eiusdem, quae operi afferant gratiam; rebus a natura ascita erunt gravitas levitas densitas puritas, contra vetustatem virtus, 
Cada uno de estos elementos es la condición de posibilidad de la apariencia agradable de las cosas, pero en tanto obra de su mutua integración. Así, el diseño, producto de la inteligencia, se complementa con la labor del obrero y con las posibilidades que ofrece la materia, fruto de la naturaleza: Alberti pasa aquí de los conceptos, definidos en una primera instancia, a los agentes involucrados, de un modo $\mathrm{u}$ otro, en el proceso constructivo (la mente del arquitecto, la mano del obrero, la naturaleza), dando cuenta del diálogo que se establece entre el plan pensado y ejecutado por el hombre y las leyes propias de la naturaleza. En el marco de este diálogo, de hecho, se conquista la concinnitas (armonía), traslación matemática del orden universal.

Señalábamos líneas arriba que, en su definición de arquitecto, Alberti da cuenta de una dimensión "práctica", y de otra "intelectual". Estas dos dimensiones de la arquitectura figuran en el inicio de una de las fuentes — ya citada- del tratado albertiano: De architectura de Vitruvio. Allí Vitruvio señala que:

La Arquitectura es una ciencia adornada de otras muchas disciplinas y conocimientos, por el juicio de la cual pasan las obras de las otras artes. Es práctica y teórica. La práctica es una continua y expedita frecuentación del uso, ejecutada con las manos, sobre la materia correspondiente a lo que se desea formar. La teórica es la que sabe explicar y demostrar con la sutileza y leyes de la proporción, las obras ejecutadas. Así, los Arquitectos que sin letras sólo procuraron ser prácticos y diestros de manos, no pudieron con sus obras conseguir crédito alguno. Los que se fiaron del sólo raciocinio y letras, siguieron una sombra de la cosa, no la cosa misma. Pero los que se instruyeron en ambas, como prevenidos de todas armas, consiguieron brevemente y con aplauso lo que se propusieron. ${ }^{18}$

et similia, quae operi afferunt admirationem. Tria haec partibus pro cuiusque //usu et munere accomodanda sunt". Alberti, De re adificatoria, VI, IV, 459.

I8. Vitruvio, Los diez libros de arquitectura, I, I, 2. Compárese con la versión latina, "Architecti est scientia pluribus disciplinis et variis eruditionibus ornata, cuius iudicio probantur omnia quae ab ceteris artibus perficiuntur opera. Ea nascitur ex fabrica et ratiocinatione. Fabrica est continuata ac trita usus meditatio, quae manibus perficitur e materia cuiuscumque generis opus est ad propositum deformationis. Ratiocinatio autem est, quae res fabricatas sollertiae ac rationis pro demonstrare atque explicare potest. Itaque architecti, qui sine litteris contenderant, ut manibus essent exercitati, non potuerunt efficere, ut haberent pro laboribus auctoritatem; qui autem ratiocinationibus et litteris solis confisi fuerunt, umbram non rem persecuti videntur. At qui utrumque perdidicerunt, uti omnibus armis ornati citius cum auctoritate, quod fuit propositum, sunt adsecuti”. Vitruvio, De architectura libri decem, I.I. 
Vitruvio enumera a continuación las disciplinas en las que debe estar instruido el arquitecto: las letras, el dibujo, la geometría, la óptica, la aritmética, la historia, la filosofía, la medicina, el derecho y la astrología; todas ellas le proporcionan dignidad intelectual al arte arquitectónico, la que Alberti le atribuye a partir del término lineamenta, que, más allá del conocimiento que el arquitecto debe poseer de otras disciplinas, hace de la arquitectura una práctica con un determinante componente intelectual. ${ }^{19}$

Vitruvio da asimismo otra definición de la arquitectura en la que establece sus componentes: "La Arquitectura consta de ordenación, que en griego se llama taxis, de disposición, que los griegos llaman diáthesis, de euritmía, simetría, decoro y distribución, llamada en griego economía" ${ }^{20}$ En lo referido a la disposición, señala:

La disposición es una apta colocación y efecto elegante en la composición del edificio en orden a la calidad. Las especies de disposición que en griego llaman ideas, son icnografía, ortografía, y scenografía. La icnografía es un dibujo en pequeño, formado con la regla y el compás, del cual se toman las dimensiones, para demarcar en el terreno del área el vestigio o planta del edificio. Ortografía es una representación en pequeño de la frente del edificio futuro, y de su figura por elevación, con todas sus dimensiones. Y la scenografía es el dibujo sombreado de la frente y lados del edificio, que se alejan, concurriendo todas las líneas a un punto. ${ }^{21}$ Nacen estas tres especies de ideas de la meditación, y de la invención. ${ }^{22}$

19. En este sentido, aduce Betts: "Vitruvio intenta elevar el estatus intelectual del arquitecto tomando prestado el prestigio de otras disciplinas, y fatalmente debilita su argumento cuando ubica fabrica antes que ratiocinatione [...]. En De re adificatoria, el arquitecto deviene un intelectual por lo que hace, y no porque debió tomar prestado el prestigio de otras disciplinas". Betts, "On Lineamentis", 433. De la dimensión intelectual del concepto de lineamenta albertiano se ocupa también el trabajo, aún no consultado, de Nikolaos-Ion Terzoglou, "The Human Mind and Design Creativity: Leon Battista Alberti and lineamenta", en The Humanities in Architectural Design: A Contemporary and Historical Perspective, eds. Soumyen Bandyopadhyay, Jane Lomholt et al. (Londres y Nueva York: Routledge, 2010), I36-I46.

20. Vitruvio, Los diez libros de arquitectura, I, II, 8. "Architectura autem constat ex ordina-

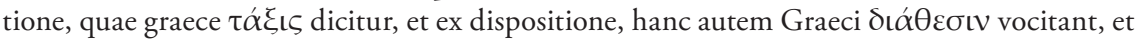
eurythmia et symmetria et decore et distributione, quae graece oikovo $\mu$ í $\alpha$ dicitur". Vitruvio, De architectura, I.2.

2I. Las tres definiciones que da Vitruvio corresponden, respectivamente, a la planta, el alzado y la perspectiva.

22. Vitruvio, Los diez libros de arquitectura, I, II, 9-Io. Compárese con la versión latina, "Dispositio autem est rerum apta conlocatio elegansque compositionibus effectus operis cum 
De acuerdo con Betts, si bien Alberti no usa esta definición "griega" de Vitruvio, en la dispositione encontró una descripción de dibujo como mediador entre la mente del arquitecto y las formas materiales del edificio. ${ }^{23}$ En efecto, en el libro II, dedicado a los materiales, Alberti retoma la importancia del "esbozo", como un paso previo a la ejecución de la obra, en estrecha conexión con el ejercicio de praecogitare (premeditar). En este sentido, dice Alberti, "Será tarea de los expertos concebir y determinar con anticipación (praecogitasse et praefinisse) cada cosa" ${ }^{24}$ Esta "fractura" entre el momento de la proyección y el momento de la ejecución ${ }^{25}$ responde a la conciencia de una fragilidad existencial que el hombre puede combatir mediante una apelación intensiva a la razón. Esta apelación se concentra particularmente en el momento destinado a la formulación del diseño de la obra:

No me cansaré por tanto de recomendar aquello que solían hacer los mejores constructores: meditar y volver a considerar la obra a emprender en su conjunto y las medidas de cada una de las partes, sirviéndonos no sólo de los dibujos y esbozos, sino también de los modelos hechos en madera u otro material, además de tener en cuenta el consejo de expertos; sólo luego de tal examen podremos hacer frente a los gastos y al cuidado de la empresa. ${ }^{26}$

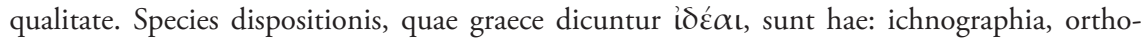
graphia, scaenographia. ichnographia est circini regulaeque modice continens usus, e qua capiuntur formarum in solis arearum descriptiones. orthographia autem est erecta frontis imago modiceque picta rationibus operis futuri figura. item scaenographia est frontis et laterum abscedentium adumbratio ad circinique centrum omnium linearum responsus. hae nascuntur ex cogitatione et inventione". Vitruvio, De architectura libri decem, I.2.

23. Betts, "On Lineamentis", 433.

24. "Bene quidem consulti est omnia praecogitasse et praefinisse animo ac mente". Alberti, De re adificatoria, II, I, 95. El "cogitare", en este último sentido, no sólo se complementa con el "agere" sino también con el "praecogitare". Vale decir, no sólo se induce a "pensar" y "meditar", antes de ejecutar una obra, sino también a "pensar de antemano", a "premeditar". La factibilidad de la obra depende en este sentido de un robustecimiento de la idea, labrada con minuciosidad al igual que, posteriormente, la materia.

25. Separación que también recomienda el proteico dios Momo a Júpiter, cuando éste decide emprender la tarea de refundar el mundo, en la narración albertiana.

26. "Iccirco vetus optime aedificantium mos mihi quidem semper probabitur, ut non perscriptione modo et pictura, verum etiam modulis exemplariisque factis asserula seu quavis re universum opus et singulae cunctarum partium dimensiones de consilio instructissimorum iterum atque iterum pensitemus atque examinentur, priusquam quid aliud aggrediare, quod impensam aut curam exigat". Alberti, De re adificatoria, II, I, 97. 
La maqueta o el dibujo del arquitecto difiere en tal sentido del propio del pintor, en la medida en que encarna el momento de la concepción, por un lado abierto a la alteración del proyecto, ${ }^{27}$ y por el otro, expuesto a una evaluación de las medidas de la obra:

Es mejor, por tanto, que se hagan modelos no ya perfectamente acabados, pulidos e ilustrados, sino desnudos y sencillos, en los que puedas juzgar el ingenio de la concepción (inventoris ingenium), no la habilidad del obrero ( fabri manum). Entre la obra gráfica del pintor y la del arquitecto existe esta diferencia: aquel se esfuerza en dar relieve por medio de sombras, líneas y ángulos disminuidos; el arquitecto, en cambio, despreciando las sombras, representa el relieve mediante el dibujo de la planta, y muestra en otros dibujos la forma y la extensión de cada fachada y de cada lado sirviéndose de ángulos reales y de líneas invariables, como quien quiere que su obra no sea juzgada con base en apariencias visuales, sino evaluada con base en medidas (dimensionibus) determinadas y racionales. ${ }^{28}$

En este praecogitare, materializado en la proyección del modelo, el arquitecto reúne su invención con la reflexión sobre la vicissitudo humana, vale decir, no sólo evita los errores que puedan existir en la concepción de la obra, sino también los imprevistos derivados de (e inherentes a) la propia vida. De allí que, al sintetizar el contenido de los primeros cinco libros del tratado, en el inicio del libro sexto, Alberti sostenga que la firmitas y la utilitas de la obra fueron el resultado de la elaboración del diseño y de su ejecución, a los fines de "resistir las inclemencias del tiempo", más precisamente, "sus injusticias (ferendam iniuriam tempestatum)":

Se ha hablado en los primeros cinco libros del diseño del edificio, de los materiales de la construcción, de la mano de obra, de todo aquello que nos pareció importante a los

27. "Y en este modelo será posible, sin peligro alguno, agregar, quitar, cambiar, innovar, aún alterar enteramente el proyecto, hasta que todo esté en su sitio y reciba nuestra aprobación". ("Et licebit istic impune addere diminuere commutare innovare ac penitus pervertere, quoad omnia recte conveniant et comprobentur".) Alberti, De re adificatoria., II, I, 97.

28. "Quare modulos velim dari non exacto artificio perfinitos tersos illustratos, sed nudos et simplices, in quibus inventoris ingenium, non fabri manum probes. Inter pictoris atque architecti perscriptionem hoc interest, quod ille prominentias ex tabula monstrare umbris et lineis et engulis comminutis elaborat, architectus spretis umbris prominentias istic ex fundamenti descriptione ponit, spatia vero et figuras frontis cuiusque et laterum alibi constantibus lineis atque veris angulis docet, uti qui sua velit non apparentibus putari visis, sed certis ratisque dimensionibus annotari". Alberti, De re adificatoria, II, I, 99. 
fines de la construcción de obras públicas y privadas, sacras y profanas, de modo de volverlas resistentes a las inclemencias del tiempo y adecuadas a las varias funciones (usus) que la diversidad de lugares, climas, personas y cosas exigen. ${ }^{29}$

Esta resistencia (en sentido material, pero también moral) se construye en la teoría arquitectónica albertiana en la asociación del diseño (lineamenta) y los materiales (materia), dos elementos complementarios, pero sujetos a una valoración jerárquica. Alberti expresa esta jerarquía mediante "la fractura voluntaria" de ambos momentos integrantes del quehacer constructivo, siendo el diseńo aquel que, apelando a la razón (a la meditación y a la premeditación), otorga su fuerza e integridad a la obra: asegura no sólo su existencia sino también su supervivencia:

En efecto, la lluvia está siempre lista para dañar y no pierde nunca la más mínima ocasión para causar males: perfora con delicadeza, reblandece, corroe constantemente todas las ligaduras del edificio, en fin, arruina por completo la construcción y la echa abajo. Por este motivo, los arquitectos experimentados pusieron buen cuidado en procurarle al agua de la lluvia un camino por donde fluyera libremente, para evitar que se detuviese en algún lugar o que penetrara por algún sitio en donde causara daño. ${ }^{30}$

Esta valoración de la dimensión intelectual de la teoría arquitectónica albertiana, sin embargo, lejos de denostar la materia, le asigna un destacado papel, que da cuenta de la alianza entre la reflexión "abstracta" del arquitecto ${ }^{3 \mathrm{I}}$ y la indagación concreta en la experiencia.

29. "Lineamenta et materiam operum et manum fabrilem, et quae ad publica privataque cum sacra tum et profana aedificia constituenda pertinere videbantur, quoad essent ea quidem ad ferendam iniuriam tempestatum apta et ad suos quaeque usus pro locorum temporum hominumque rerumque rationibus accommodata”. Alberti, De re adificatoria, VI, I, 44I.

30. "Nam semper quidem est ad lendendum paratus imber et aditus ad maleficium quamvis minimos nunquam non usurpat: etenim tenuitate perterebrat, mollitie inficit, assiduitate commacerat omnes aedificii nervos, denique structuram funditus vitiat atque perdit. Ea de re probe observarunt periti architecti, ut liberum fluendi cursum imbribus pararent, caverentque, ne quo loci aqua consisteret, aut uspiam pervaderet, quo noxam inferret". Alberti, De re adificatoria, I, XI, 77-79.

3I. Esta palabra se entrecomilló, ya que el término "abstracto" no responde con exactitud a la elaboración mental (plasmada por otra parte en la maqueta) del arquitecto; es pertinente, en su lugar, para graficar el saber especulativo de los filósofos, tal como son caracterizados en el Momus. Recurrí a esta palabra, sin embargo, para diferenciarla del estadio anterior a la obra consumada, con el empleo concreto de los materiales. 


\section{Los materiales}

En efecto, no sólo el diseño de la obra asegura la pervivencia de la construcción, su sustracción de los avatares del tiempo y de las inclemencias de la naturaleza, sino también la selección de los materiales en virtud de sus cualidades intrínsecas, evaluadas a partir de la observación y la experiencia. Así, estudiando las construcciones de los antiguos, se pueden diferenciar el valor y la fuerza de los distintos tipos de piedra, tanto como la experiencia ha permitido dictaminar que las maderas se fortalecen y se tornan más aptas para trabajarse si se las espolvorea con tierra, se las encera y se las coloca determinado tiempo sobre trigo. ${ }^{32}$

De hecho, para contrarrestar la potencia devastadora de la naturaleza, Alberti no sólo recurre a la técnica del arquitecto, sino que deposita su atención también en los propios materiales a utilizar. Esta importancia dada por Alberti a los materiales para detener la acción destructora de la naturaleza ha llevado a Cassani a argumentar que la resistencia de la obra depende, también, de la materia, en la que se "sustancia la forma y el diseño" elaborado por el arquitecto. De acuerdo con su lectura, en lugar de presentar una fractura entre lo intelectual y lo material, Alberti “porque es consciente de la 'ontológica' debilidad de la materia” le presta la máxima atención. ${ }^{33}$ En efecto, la materia, como afirma Cassani, participa de la misma vicissitudo temporum de los hombres, tal y como se evidencia en las ruinas de la antigüedad. Alberti, considerando la evidente centralidad de la dimensión material del edificio, por ello mismo, no sólo busca los materiales más dúctiles y resistentes, por medio de una indagación en la experiencia, sino que, sobre todo, se muestra consciente de la contención que debe procurarles a éstos el diseño. Es en el libro primero, dedicado al diseño, donde da un ejemplo paradigmático de la asociación que debe establecerse entre las inclemencias del tiempo y la resistencia constructiva:

La utilidad de la techumbre es la primera y más importante de todas. En efecto, no sólo contribuye a la salud de los habitantes, al rechazar y apartar la noche, la lluvia y sobre todo el sol, sino que también protege (tuetur) maravillosamente todo el edificio. [...]. Sin duda, la techumbre es el arma que los edificios tienen contra las inclemencias y el ataque del tiempo (tempestatum iniurias atque impetus). ${ }^{34}$

32. Alberti, De re adificatoria, II, VIII y II, V.

33. Cassani, La fatica del costruire, i I7.

34. "Tectorum utilitas omnium est prima et maxima. Non enim solum incolarum saluti confert, dum noctem imbremque atque in primis aestuantem solem repellunt atque excludunt; 
Esta fractura intencional entre el momento de la elaboración del diseño y su materialización es justamente lo que permite sustraer a la materia de la vicissitudo temporum e integrarla en un plan, vale decir, trocar su mutabilidad en firmeza y duración, su constante devenir en un principio de estabilidad. Es en este sentido que el espacio diseñado humanamente (la arquitectura) se constituye en una de las principales herramientas de lucha contra los estragos de la naturaleza y del tiempo, en la medida en que éste, como aquélla, corrompe la materia con el paso de los años y de la violencia propiciada por los hombres mismos. ${ }^{35}$ Alberti, en efecto, se muestra apesadumbrado por la debacle de la cultura antigua, que se manifiesta en el estado ruinoso de los edificios y sus soportes intelectuales:

Me dolía que tan abundantes e ilustres documentos de los escritores se hubiesen perdido por la adversidad de los tiempos y de los hombres; a punto tal que, en medio de tanta ruina, una sola obra se hubiera salvado llegando hasta nosotros, aquella de Vitruvio: escritor ciertamente muy competente, pero tan estropeado y lacerado por el paso del tiempo, que en muchos pasajes se advierten lagunas e imperfecciones. ${ }^{36}$

verum et mirifice omne tuetur aedificium. [...]. Arma nimirum aedificiorum tecta sunt contra tempestatum iniurias atque impetum”. Alberti, De re adificatoria, I, XI, 75.

35. En contraste con la búsqueda de armonía y estabilidad que Alberti plasma en De re adificatoria, el comportamiento violento e irracional del hombre se pone en primer plano en sus obras literarias, particularmente, en Momus y las Intercenales. Es Garin quien se ha ocupado en primer lugar de estas dos vertientes del pensamiento albertiano. Para el filósofo italiano, si en los tratados de arte y ciencia albertianos se vislumbra "el intento de alcanzar una solución positiva de las contradicciones de la realidad", en obras como Momus o las Intercenales el humanista sostiene un "comentario irónico del drama absurdo de la vida". Trabajé sobre estas dos vertientes del pensamiento albertiano en: Mariana Sverlij, "La razón y el absurdo en la obra de Leon Battista Alberti”, Studia Aurea, núm. 6 (2012): I55-I77. consúltese en http:// studiaurea.com/article/view/v6-sverlij.

36. "Nanque dolebam quidem tam multa tamque praeclarissima scriptorum monumenta interisse temporum hominumque iniuria, ut vix unum ex tanto naufragio Vitruvium superstitem haberemus, scriptorem procul dubio instructissimum, sed ita affectum tempestate atque lacerum, ut multis locis multa desint et multis plurima desideres”. Alberti continúa sus reflexiones sobre Vitruvio de este modo: "Se ańadía el hecho de que hubiera transmitido en una lengua nada culta; de modo que los latinos dirían que quiso parecer griego, mientras que los griegos aseguran que escribió en latín. Pero el hecho basta por sí mismo para probar que no fue ni latino ni griego; lo que equivale a decir que quien escribió de un modo tal que no podemos entenderle, no escribió para nosotros". "“Accedebat quod ista tradidisset non culta: sic enim loquebatur, ut Latini Graecum videri voluisse, Graeci locutum Latine vaticinentur; res autem ipsa in sese porrigenda neque Latinum neque Graecum fuisse testetur, ut par sit non scripsisse hunc nobis, qui ita scripserit, ut non intelligamus".) Alberti, De re 
De acuerdo con Cassani, el tratamiento dado por Alberti a la restauración de los edificios forma parte de la crítica, que el humanista disemina a lo largo de su obra, de las conductas ociosas: "En mayor medida que un destructor 'activo', que puede ser representado por el furor barbarus, el hombre aparece a los ojos de Alberti como un destructor 'pasivo': el desinterés por la suerte de la arquitectura es la primera causa de la ruina de los edificios. Retorna aquí, una vez más, la condena al otium". ${ }^{37}$ En todo caso, frente al hombre destructor, por acción, pero también por omisión, emerge la figura diligente e industriosa del arquitecto, cuya meta no sólo es construir sino también reparar lo destruido.

\section{La restauración}

Alberti, como señalábamos al comienzo, fundamenta su arte desde la perspectiva de la ruina, en donde la historia se hunde y se reanima. Es por ello que ésta nunca es objeto de una contemplación pasiva. No sólo a partir de la observación de las ruinas el humanista nacido en Génova busca ciertos principios de estabilidad, a los que llama la res adificatoria. Sabe que la materia es frágil, y que todo lo terreno en algún momento se halla sujeto al derrumbe. Resulta en tal sentido significativo que a la atribución albertiana de la ruina como modelo y moraleja le corresponda, en el final del tratado, el abordaje del mantenimiento y la restauración de los edificios, lacerados por la impericia humana, y por los estragos devastadores de la naturaleza y del tiempo.

Más allá de las controversias sobre la génesis y el lugar que ocupa el libro X en el proyecto original albertiano, ${ }^{38}$ lo cierto es que en él Alberti se ocupa de una

adificatoria, V, I, 44I. El estado maltrecho del texto vitruviano responde también, pues, al lenguaje incomprensible utilizado por el propio Vitruvio, a mitad de camino entre el griego y el latín y violatorio, por tanto, de la latinitas, que junto con la perspicuitas, el ornatus y el decorum integra las virtutes dicendi: de hecho, a lo largo de su tratado, Alberti se esmera en retratar el arte de la arquitectura con la mayor claridad expresiva posible, debiendo para ello, en ocasiones, emplear nuevos vocablos allí donde no alcanzan las palabras usuales. "Habré de acuñar denominaciones para ser lo más accesible y menos oscuro posible, como he procurado que debía ser en estos libros". ("Fingenda mihi erunt nomina, quo sim, quem esse me his libris maxime elaborandum institui, facilis et minime obscurus"), III, XIV, 24I. En este mismo sentido se expresa en el último capítulo del libro VI.

37. Cassani, La fatica del costruire, I38-I39.

38. Para Grayson, Alberti no sólo presentó en 1452 a Nicolás V el tratado en su conjunto, con sus diez libros, sino que éstos fueron escritos de un tirón. Cecil Grayson, Studi su 
fase distinta y emparentada con el arte de la construcción propiamente dicho: el mantenimiento y la restauración de los edificios. En efecto, Alberti da cuenta de los dos rostros que lleva implícitos el arte arquitectónico: la construcción y la destrucción. A esta doble faz que rodea todo aquello que existe en el "mundo sublunar", se acopla una tercera posibilidad (vanamente proclamada en Momus por Júpiter): la de la restauración. El libro décimo del tratado, en este sentido, dialoga con los libros primero y segundo dedicados al diseńo y los materiales, dejando en evidencia que el programa impuesto por la razón no siempre vence a las vicisitudes de un mundo dominado por lo absurdo y que, del mismo modo, este mundo irracional no siempre se impone cuando se anteponen los recursos de la razón. Es así como en el libro X Alberti analiza los defectos que puede presentar una construcción, una vez realizada, y los divide entre aquellos que se derivan de causas externas, fundamentalmente ligadas al accionar de la naturaleza, y aquellos que provienen de causas internas, vinculadas a la concepción o a la ejecución del edificio. Alberti plantea aquí un dilema sustancial: ¿̇todo lo puede enmendar la mano y el raciocinio humanos? La respuesta, evidentemente, es negativa:

Pero no todos los defectos que tienen su origen en causas externas son de tal naturaleza que no puedan ser corregidos; y tampoco los defectos propios del arquitecto pueden siempre corregirse. En efecto, las obras que están estropeadas por completo y desfiguradas en todas sus partes no son susceptibles de recibir mejoras. Asimismo, en cuanto a las que se encuentran en un estado tal que no pueden ser mejoradas

Leon Battista Alberti (Città di Castello: Olschki, 1998). Distinta es la hipótesis formulada por Zoubov, según la cual Alberti redactó su tratado libro por libro, ofreciendo a Nicolás V, no la totalidad del tratado, sino los dos primeros libros, eventualmente acompañados por el libro décimo: "Es probable que los dos primeros libros y el libro $\mathrm{X}$ hayan sido mostrados por el autor al papa Nicolás V ya en 1952. Los libros III, IV y V no estaban aún terminados en ese momento. Los libros VI y IX fueron escritos en I 455-I 472". Vasiliï Zoubov, "Leon Battista Alberti (I 404I472) et les auteurs du Moyen Âye", Medieval and Renaissance Studies, vol. 4 (I958): 245-66. Caye, en cambio, sostiene que los dos últimos capítulos del libro $\mathrm{X}$ no sólo son extranjeros al tratado de arquitectura albertiano, sino anteriores a éste. Se trata, desde su lectura, de un primer esbozo de las descripciones que Alberti retomará luego de un estudio mucho más profundo sobre la cuestión, habiendo sido agregados con probabilidad por copistas que los recuperaron para completar el libro X. Como el propio Caye cita, Max Theuer, traductor alemán del De re adificatoria, sostiene que este último libro, en su totalidad, se escribió aparte y con fines divergentes al resto del tratado, una hipótesis descartada por Grayson en función de las numerosas alusiones, diseminadas a lo largo del tratado, al problema de la restauración de los edificios. Pierre Caye, "La Place du livre X dans le De re adificatoria", Albertiana, núm. 7 (2004): 23-40. 
sino trastrocando su entero diseño, su reparación no es preferible a su demolición y posterior reconstrucción".39

Alberti promete abocarse a aquellos edificios que en efecto se pueden reparar, dando un lugar primordial, entre ellos, a los públicos. En este sentido, comienza señalando los posibles mejoramientos que se pueden introducir, si la primera de las seis partes que conforman la arquitectura (la regio) hubiera estado mal escogida, vale decir, si hubiere sido erróneo el medio ambiente elegido para el emplazamiento de la ciudad. Una vez constatada esta deficiencia, el arquitecto puede subsanar los problemas acarreados a la construcción por un entorno adverso. Alberti se detiene en este primer aspecto, dejando la impresión de un libro inacabado, ya que en lo siguiente se centrará en los modos y opciones de obtención y canalización del agua, a excepción de los dos últimos capítulos en los que se dedica a analizar los defectos y la reparación de los muros.

La restauración, sin embargo, no sólo supone una adición suplementaria a las explicaciones del tratado, que da cuenta de las posibles soluciones frente al desmejoramiento de las obras, sino que también, desde la interpretación de Pierre Caye, permite redimensionar el concepto de lineamenta, del que Alberti se ocupa en el libro primero. En este sentido, de acuerdo con Caye:

No se trata más de concebir in mente, en el atelier mental del arquitecto, un proyecto completo, autosuficiente, seclusa materia, en la pura abstracción de toda materia y de toda contingencia [...] — modo de concepción extraído del modelo de la creación divina - sino de hacer un llamado a un modus inveniendi mucho más modesto, fundado en el simple desplazamiento de líneas o de elementos estructurales, en la modificación de medidas o masas, en la sustitución, adición o sustracción de las partes en relación a lo existente. ${ }^{40}$

Creo, sin embargo, que en la confianza depositada en el arte arquitectónico, Alberti persigue los fundamentos de una nueva vivendi ratio, algo que en el trata-

39. "Sed non omnia, quae importantur aliunde, vitia talia sunt, ut emendari nequeant; neque ad architecto si quod aderit vitium, tale semper erit, emendari ut queat. Corrupta enim funditus et omni ex parte penitus depravata emendationes non suscipiunt. Quae item sic se habent, ut, nisi totis lineis pervertantur, reddi nequicquam possunt meliora, ea quidem non emendantur magis quam, ut nova illic facias, demoliuntur". Alberti, De re adificatoria, X, I, 87 I.

40. Caye, "La Place du livre X", 3 I. 
do se vislumbra a partir de una arquitectura que se adjudica las tareas propias de la retórica: persuadir para inducir a una acción transformadora. No me ocuparé en este artículo de esta dimensión central de la teoría arquitectónica albertiana, que, por otra parte, debe contemplarse en el diseño de la construcción. Baste subrayar que en el inicio del libro VI, Alberti vuelve a remitirse a la famosa tríada vitruviana (firmitas-commoditas-amoenitas) para argumentar el recorrido emprendido en los primeros cinco libros y justificar el contenido de los que restan, imponiéndole una jerarquía a estos tres criterios a los que debe subordinarse la construcción: el conseguir la gratia y la amoentitas se revela, en esta ocasión, sin embargo, una empresa aún más destacada en el arte de la construcción que la obtención de la firmitas y la utilitas. En efecto, señala Alberti:

De las tres partes que atañían a la técnica de la construcción en su totalidad (universam aedificationem) —que los edificios sean adecuados a los usos (usum) que les vayamos a dar, que tengan la máxima solidez y duración (perpetuitatem firmissima), que posean gracia y hermosura (gratiam et amoenitatem) — hemos terminado de abordar las primeras dos. Resta por tanto la tercera, que de todas es la más noble, además de indispensable. ${ }^{4 \mathrm{I}}$

La belleza, fruto de la armonía de las proporciones y del ornamento, de hecho, no sólo procura deleitar, desde un punto de vista estético, sino también conmover para inducir a una acción virtuosa. ${ }^{42}$

4I. "Ex tribus partibus, quae ad universam aedificationem pertinebant, uti essent quidem quae adstrueremus ad usum apta, ad perpetuitatem firmissima, ad gratiam et amoenitatem paratissima, primis duabus partibus absolutis restat tertia omnium //dignissima et perquam valde necessaria”. Alberti, De re adificatoria, VI, I, 445.

42. En palabras de Alberti: "En efecto, ¿quién negará sentirse más a gusto cuando habita entre paredes adornadas que cuando lo hace dentro de muros descuidados? O, ¿por qué otro medio más seguro el arte humano podrá proteger sus productos de las ofensas del propio hombre? Porque la belleza hará que la ira destructora del enemigo se calme y la obra de arte sea respetada". ("Quis enim non secum agi commodius affirmabit, ubi sese inter ornatos, quam si neglectos intra parietes receperit? Aut quid alioquin tam obfirmatum effici //ulla hominum arte poterit, quod ab hominum iniuria satis munitum sit? At pulchritudo etiam ab infestis hostibus impetrabit, ut iras temperent atque inviolatam se esse patiantur"). Alberti, De re adificatoria, VI, II, 447. 


\section{El patrimonio antiguo: advertencia y compasión}

La ruina representa, en todo caso, un espacio de reunión de la temporalidad pasada (en su esplendor y en la debacle del mismo) y de la actual (en su carácter derruido y en su promesa de reconstrucción). Según he analizado, desde este punto de vista, Alberti reflexiona sobre la estructura secular del mundo, en términos de la historia construida y vuelta a construir, pues es una absurda ilusión creer en la firme vocación constructiva de los hombres y, en este mismo sentido, en la fortaleza y durabilidad de sus obras. ${ }^{43}$ En efecto, la escritura que emerge desde la ruina lleva en sus entrañas la conciencia de la fragilidad de toda obra humana. Es por ello que tampoco la Antigüedad, y ni aún la naturaleza, logran escapar a este ciclo de fatalidad. ${ }^{44}$ Quedan, no obstante ello, rastros de un saber, fruto de la experiencia atravesada por los hombres. La historia en tal sentido no sólo se manifiesta por medio del rostro de la violencia sino que también deja entrever - desde sus mismas fisuras — los rastros de una sabiduría que el arquitecto debe hacer propia, expresando en su labor (y en el resultado de su labor) una prudencia que combina una actitud estoica y una voluntad de intervención civil. La obra de Alberti enseña, en este sentido, que no se trata de renunciar al mundo (al modo del Petrarca de la Vita solitaria) o, por el contrario, de adentrarse activamente en él (al modo del mentado por Hans Baron "humanismo

43. Grassi sostiene que el humanismo renacentista contrapone a la visión metafísica de la filosofía tradicional una concepción del hombre en su discurrir histórico y existencial. Al trabajar particularmente con el Momus albertiano señala: "Momo proclama con su espíritu crítico la abolición del orden eterno y ahistórico imperante hasta ese momento. La historia penetra en la esfera de lo siempre idéntico, con lo que se confirma que es Momo el que propiamente cuestiona el mundo divino, viéndose envuelto por esa razón en las más grotescas aventuras, sin que nadie pueda confiar en él”. Ernesto Grassi, La filosofía del humanismo, trad. Manuel Canet (Barcelona: Anthropos, I993), I79.

44. En un sentido similar, en el prólogo a la versión en vulgar del tratado De Pictura (Della Pittura) dedicado, precisamente, al arquitecto Filippo Brunelleschi, Alberti, al parangonar las obras de la Antigüedad con las de su tiempo, se figura a una naturaleza "envejecida y cansada” ("fatta antica e stracca") que ya no logra producir ingenios como los antiguos. Este melancólico comienzo es, sin embargo, inmediatamente superado, cuando el humanista recuerda su vuelta a Florencia luego del largo exilio al que fueron condenados los Alberti, ocasión en la que pudo contemplar la manifestación de un renovado espíritu debido a las obras de Brunelleschi, Donatello, Ghiberti, Luca della Robbia y Masaccio. Leon Battista Alberti, De Pictura, en Opere Volgari, ed. Cecil Grayson, vol. 3 (Bari: Laterza, I973), 7-8. 
civil”), ${ }^{45}$ sino de reconocer la conciencia simultánea de la falta de conducción del propio mundo y el anhelo de imprimir en él una planificación humana.

Esta planeación sólo puede vislumbrarse por medio de la ruina, que expresa los incesantes intentos de construcción y reconstrucción de la historia. El sentimiento de pesar ante el estado ruinoso de las cosas, en este sentido, expresa en la obra albertiana, al mismo tiempo, la búsqueda de control sobre los sucesos por venir. Este control que se obtiene en el marco de una apelación a la razón, que contiene y da forma al transfondo absurdo de la vida. De allí que en el inicio del libro VI, Alberti sitúe al lado de la ardua labor que le ha significado escribir su tratado sobre el arte edificatorio, el dolor que le producía ver el estado de los edificios antiguos, un espectáculo desolador al que non sine lachrymis videbam. En efecto, el humanista — tal como allí confiesa—impulsado por esa compasión que le generaban los restos sobrevivientes de la Antigüedad, emprendió su labor de escritura, reponiendo las faltas e inconsistencias de las fuentes, inventando nuevos vocablos donde no los había, y desafiando, finalmente, las propias limitaciones que encontraba. En la Retórica, Aristóteles define la compasión como

un cierto pesar por la aparición de un mal destructivo y penoso en quien no lo merece, que también cabría esperar que lo padeciera uno mismo o alguno de nuestros allegados $[\ldots]$ porque está claro que el que está a punto de sentir compasión necesariamente ha de estar en la situación de creer que él mismo o alguno de sus allegados van a sufrir un mal y un mal como el que se ha dicho en la definición, o semejante, o muy parecido. ${ }^{46}$

De allí que, según Aristóteles, no experimenten compasión aquellos que están completamente perdidos, o bien, enteramente satisfechos. La compasión tiene un uso retórico, en este sentido, al estar emparentada con el propio miedo, persuadiendo a los hombres a medir sus futuras acciones, con el fin de evitar

45. Subraya Baron que "el humanismo del siglo xiv, que había mantenido las características medievales de un alejamiento del mundo, se transformaba ahora en humanismo civil". Hans Baron, En busca del humanismo cívico florentino (México: Fondo de Cultura Económica, 1993), I9. El soporte material de esta nueva experiencia lo aportan, principalmente, los trabajos de Leonardo Bruni, en particular, su Laudatio de la ciudad de Florencia y el segundo de sus Diálogos a Pier Paolo Vergerio, ubicado cronológicamente por Baron con posterioridad a I 402 y, por consiguiente, a la muerte de Giangaleazzo Visconti.

46. Ret. II, 8, I385b I3-I9. Reproducimos la traducción de Quintín Racionero, Aristóteles, Retórica (Madrid: Gredos, 2007), 195. 
que se cierna sobre ellos el mal que abatió a quien resulta objeto de la compasión. En términos albertianos, este estatuto persuasivo de la compasión tiene su origen en la conciencia del desamparo humano, que hermana a los hombres entre sí en su común fragilidad. En efecto,

Lo efímero no está entonces solamente en la naturaleza, a la que el arte superpone su durabilidad y solidez; está también en la violencia de la historia, amenazando desde el interior el proyecto arquitectural, considerado en su propia dimensión "histórica". ${ }^{47}$

Para el humanista nacido en Génova, esta fragilidad de la historia encuentra una expresión simbólica y material en las antiguas construcciones, únicas capaces de ofrecer una enseñanza a las nuevas empresas constructivas. En sus notas a la Retórica de Aristóteles, Quintín Racionero aduce:

En todo caso, este mecanismo psicológico es el que fundamenta la capacidad persuasiva del uso retórico de la compasión, puesto que sobre todo nos sentimos persuadidos en aquellas ocasiones en que "más nos da la sensación de que también podría sucedernos" lo que compadecemos en otros [...]. En la experiencia del mal ajeno y como resultado del miedo propio, la piedad reintroduce la óptica del hombre que sabe que no es Dios. ${ }^{8}$

El hombre albertiano reconoce en su desamparo la ausencia de un plan mayor, en donde albergarse como una pieza designada a integrar el todo. En este sentido, apelando a la razón, diseña su propio espacio y lo preña de valores que estimulen su conservación. Consciente, sin embargo, de la fragilidad de este espacio, erigido por el hombre para el hombre, asume que es necesario considerar, también, su posible destrucción y su posterior reconstrucción, tal como se revela en la propuesta de refundación del mundo, llevada a cabo en el Momus, y en la reparación de los edificios, que Alberti contempla en el libro X de su tratado.

47. Paul Ricoeur, "Arquitectura y hermenéutica", Arquitectonics, vol. 5 (2002): 24.

48. Quintín Racionero, introducción, traducción y notas a Aristóteles, Retórica, 196-197. 


\section{Conclusiones}

De acuerdo con Richard Krautheimer, el tratado de arquitectura de Alberti, De re adificatoria, no sólo pugna por devolver a su estado original los edificios y los escritos de la Antigüedad, lacerados por el tiempo. ${ }^{49}$ La empresa propuesta por el humanista es ardua, en la medida en que implica, también, reponer un sistema global de pensamiento y de vida:

Se trate de monumentos o escritos, las obras de los antiguos, después de todo, han devenido fragmentos maltratados y destruidos por el tiempo. Por consiguiente, deben ser reconstruidos, interpretados y mejorados de acuerdo a las líneas que para Alberti representan el verdadero significado de la Antigüedad, el verdadero significado deducido de la totalidad de la Antigüedad, tal como él la reconoce: un sistema consistente de pensamiento y de vida en el cual cada cosa y cada acción se ubica en su lugar. ${ }^{50}$

Para esta labor de reconstrucción, refiere Krautheimer, Alberti se dirige en su tratado a los patrocinadores de las futuras construcciones. Estos mecenas son los de la nueva generación que debe ser educada de acuerdo a las premisas del pensamiento humanista. ${ }^{\text {I }}$ No por casualidad, continúa Krautheimer, De re adificatoria fue escrito en latín, la lengua erudita del nuevo programa, ni tampoco casualmente el texto albertiano fue emprendido a instancias de Lionello D’Este, y luego de concluido, presentado al pontífice humanista Nicolás V.52

49. Para una detallada clasificación y análisis de las fuentes de conocimiento, escritas y edilicias, mencionadas por Alberti, puede consultarse Ana Belén Onecha Pérez, "Una nueva aproximación al De re edificatoria de Leon Battista Alberti. Los conocimientos constructivos y sus fuentes", tesis doctoral (Universidad Politécnica de Cataluńa, 20I2), 69- 75 y 497-615.

50. Richard Krautheimer, "Alberti and Vitruvius", en Acts of the XXth International Congress for the History of Art. Studies in Western Art II (Princeton University Press, I963), 52.

51. Krautheimer, "Alberti and Vitruvius", 49.

52. Krautheimer, "Alberti and Vitruvius", 52. En efecto, Krautheimer encuentra una evidencia del nexo que se establece entre la escritura del tratado y las sugerencias hechas a Alberti por Lionello D'Este en el inicio del libro VI del De re adificatoria. Para Krautheimer este último sería, en realidad, un prefacio que Alberti habría escrito para una primera versión del $D e$ re adificatoria, en un momento de decepción después de haber renunciado a escribir el comentario de Vitruvio que Lionello D’Este le había sugerido. En detrimento de esta lectura, para Choay, el comienzo del libro VI, con su valor de nuevo prólogo, constituye una pieza central de la arquitectura del texto albertiano. Las observaciones que en él hace Alberti sobre la arquitectura antigua y contemporánea, el estado del texto de Vitruvio y los propósitos de utilizar en su tratado, como contrapartida, un latín correcto e inteligible, "liga la narración de los 
El particular nexo que se establece en la teoría arquitectónica albertiana entre la omnipresente conciencia de la ruina, y la atención dada al diseńo y los materiales, sin embargo, pone de manifiesto la dubitativa lectura que hace Leon Battista de los nuevos ideales humanos. Ciertamente, como aduce Krautheimer, Alberti comprende que el legado de la Antigüedad se ha convertido en ruinas y fragmentos, que es preciso reconstruir e interpretar, encomendando esta tarea al arquitecto. Pese a ello, Alberti, antes que consagrar, se tropieza en su obra con las esperanzas cifradas en el hombre. En este sentido, advierte que el nuevo orden dependerá de la conciencia de la ruina, a la que el arquitecto debe anticiparse mediante la elaboración del diseño y la selección de los materiales.

En efecto, la atención dada por Alberti al diseño y los materiales resulta inseparable de la reflexión que dedica al maltrecho estado del texto de Vitruvio y a los restos agónicos de las obras arquitectónicas de la Antigüedad. De allí que ambas reflexiones deban tomarse como una unidad, en la medida en que, desde la conciencia de la ruina, dan cuenta de un llamado conjunto a la arquitectura y a la filología, 53 no sólo desde el "sueño del humanismo", 54 sino también desde su pesadilla. En este último sentido, en el tratado de arquitectura albertiano, en lugar de ser el mecenas que encarga la obra —en su calidad de simple comitente o en tanto representante del nuevo programa humanista-, es el arquitecto el prototipo ideal de hombre que se eleva por encima del resto: su mirada se ha moldeado no al calor del triunfo, sino de la derrota, de la que pugna por emerger. \$

momentos de la edificación a la de la reflexión que la construye, hace correr paralelamente el tiempo teórico del constructor y el tiempo del escritor”. Françoise Choay, La Règle et le modèle. Sur la théorie de l'architecture et de l'urbanisme (París: Edition du Seuil, I996), I I9.

53. De acuerdo con Eck, del mismo modo que De oratore de Cicerón no representa una guía para la exitosa articulación del discurso público, sino una interrogación sobre la verdadera naturaleza de la elocuencia y su papel en la sociedad, el De re adificatoria no es una colección de instrucciones que debe seguir el constructor, sino un interrogarse sobre los principios de la arquitectura, considerada como un instrumento esencial para la sociedad civilizada. Caroline van Eck, "The Structure of 'De re ædificatoria' Reconsidered", Journal of the Society of Architectural Historians, núm. 3 (I998): 280- 297.

54. Tal es el título del estudio que Rico dedica al humanismo. Francisco Rico, El sueño del humanismo. De Petrarca a Erasmo (Madrid: Alianza, 1993). 